\title{
An Antisense Oligonucleotide Reverses the Footshock-Induced Expression of Fos in the Rat Medial Prefrontal Cortex and the Subsequent Expression of Conditioned Fear-Induced Immobility
}

\author{
Bret A. Morrow, ${ }^{2}$ John D. Elsworth, ${ }^{1,2}$ Fiona M. Inglis, ${ }^{2}$ and Robert H. Roth ${ }^{1,2}$ \\ Laboratory of Neuropsychopharmacology, Departments of ${ }^{1}$ Pharmacology and ${ }^{2}$ Psychiatry, Yale University School of \\ Medicine, New Haven, Connecticut 06520-8066
}

\begin{abstract}
The immediate-early genes, including $c$-fos, have been proposed to be involved in learning and memory. In this report, we examine stress-induced Fos-like immunoreactivity (Fos-li) in subregions of the prefrontal cortex during a conditioned fear paradigm. During the acquisition phase, the rats were conditioned to fear a formerly neutral tone by pairing the tone with a mild footshock. The rats were then tested for fearful behavior by reexposure to the tone without additional footshock. During acquisition, Fos-li was increased in the medial prefrontal cortex (infralimbic and prelimbic) but not the anterior cingulate and M1 motor cortex. However, during the extinction phase, no significant increase in Fos-li was observed in any region. These findings indicate that acquisition, but not extinction, of conditioned fear is associated with an increase in Fos-li in subregions
\end{abstract}

c-fos is an oncogene in the early-immediate gene family encoding for the Fos protein, which is capable of forming heterodimers with protein products of the $c$-jun transcription family. These dimers bind to the AP-1 site on DNA and regulate the transcription of other genes (Morgan and Curran, 1991; Hoffman et al., 1992). The activation of the immediate-early gene products appears to be a mechanism by which brief stimuli can trigger long-term changes in genetic expression and, thus, alter the neuronal response to subsequent events. The expression of the oncogene $c$-fos has been noted to increase in rat brain tissue in response to different stressors, including restraint (Deutch et al., 1991; Schreiber et al., 1991; Melia et al., 1994), footshock (Smith et al., 1992), and several animal behavioral models of anxiety (Duncan et al., 1996). Other stimuli that were not deliberately stressful can result in increased production of Fos, including isotonic saline injections (Sharp et al., 1991; Asanuma and Ogawa, 1994), handling (Campeau et al., 1991), cocaine administration (Graybiel et al., 1990; Young et al., 1991), and brushing vibrisea (Mack and Mack, 1992).

Because immediate-early genes have been proposed to be involved with long-term modifications in neuronal biochemistry or structure thought to underlie learning (for review, see Dragunow,

Received Feb. 16, 1998; revised April 12, 1999; accepted April 19, 1999.

This work was supported in part by National Institutes of Health Grants MH14092 and DA-11288. We thank Dr. Csaba Leranth and Marya Shanabrough for their excellent technical advice and assistance.

Correspondence should be addressed to Dr. Bret A. Morrow, Department of Pharmacology, Yale University School of Medicine, 333 Cedar Street, New Haven, CT 06520-8066.

Dr. Inglis's present address: Department of Neurology, Yale University School of Medicine, 333 Cedar Street, New Haven, CT 06520-8018.

Copyright (C) 1999 Society for Neuroscience $0270-6474 / 99 / 195666-08 \$ 05.00 / 0$ of the medial prefrontal cortex. In other animals, an antisense oligonucleotide directed against the c-fos mRNA was injected into the infralimbic/prelimbic cortex 12 or $72 \mathrm{hr}$ before the acquisition session. Antisense treatment given 12, but not 72 , hr earlier suppressed Fos production without altering behavior during the acquisition session. Three days after the acquisition session, rats were tested for fearful behavior as before. The antisense oligonucleotide blockade of Fos production during acquisition was associated with a significantly less fearful response during the extinction session. These results support a role for Fos in the medial prefrontal cortex during the acquisition of aversive learning.

Key words: immediate-early gene; learning; AP-1; c-fos; infralimbic cortex; prelimbic cortex
1996), we have examined to use Fos activation in the acquisition and the extinction of conditioned fear, a model of aversive learning. The conditioned fear protocol consisted of an acquisition session in which the subject is taught to fear a tone by pairing it with a brief footshock and an extinction session in which the conditioned fearfulness is tested by exposing the subject to the tone without footshock. Our expectation was that Fos-like immunoreactivity (Fos-li) may be helpful in identifying prefrontal cortical subregions in which potential cellular changes involved in learning an aversive behavioral response may occur. The medial prefrontal cortex (mPFC) was selected as a target because of its involvement in the biochemical response to stress (for review, see Deutch and Roth, 1990) and its proposed role in cognition and higher memory functions (Goldman-Rakic, 1987; Posner, 1994). In a second issue, the role of the stress activation of Fos in the mPFC was investigated by suppressing the expression of the Fos protein using a DNA antisense oligonucleotide (ASO) that is complementary to the Fos mRNA. Previously, this technique has been used successfully to suppress Fos production (Chiasson et al., 1992; Heilig et al., 1993; Hooper et al., 1994; Moller et al., 1994; Hunter et al., 1995). In this way, the role of the stressinduced activation of Fos during the acquisition of an aversive memory can be tested.

\section{MATERIALS AND METHODS}

Animals. Adult male Sprague Dawley rats (Camm Laboratories, Wayne, $\mathrm{NJ}$ ) weighing between 200 and $250 \mathrm{gm}$ were used in all experiments. Rats were housed two per cage on a $12 \mathrm{hr}$ light/dark schedule (8:00 A.M. lights on). Food and water were supplied ad libitum in the home cage. Rats were brought into the facility at least $7 \mathrm{~d}$ before the start of the experiment to allow adaptation after traveling to the facility.

Apparatus. The testing apparatus was a Plexiglas and stainless steel box 
Table 1. Fear conditioning protocol

Control

Acquisition

Extinction

Habituation

Day 1

Day 2
$3 \times 30$ min daily sessions without tones or footshock

No tones or footshock

10 tones
No tones or footshock

10 tones paired with footshock
10 tones paired with footshock 10 tones

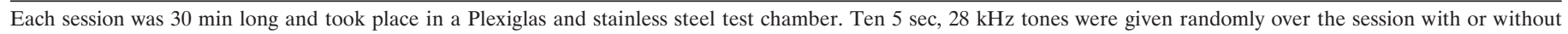
a $0.5 \mathrm{sec}, 0.8 \mathrm{~mA}$ footshock.

$(24 \times 30 \times 27 \mathrm{~cm})$ with a stainless steel bar floor contained in a isolation chamber to minimize external influences. The cages were lit indirectly by a dim red light. A white noise generator provided a constant background noise, and the cages were cleaned and dried before each session with $70 \%$ ethanol to minimize olfactory cues. The bar floor was wired for scrambled footshock, and the intensity was calibrated to $0.8 \mathrm{~mA}$ (Morrow et al., 1996). The conditioned stimulus was a $2.8 \mathrm{kHz}$ tone lasting $5 \mathrm{sec}$. The tone itself was $\sim 5 \mathrm{~dB}$ above background noise and alone does not visibly startle the rats. The unconditioned stimulus was a $0.5 \mathrm{sec}$ scrambled footshock timed to terminate at the same time as the tone. Ten trials per each $30 \mathrm{~min}$ session were used, with the intertrial intervals randomly selected by a personal computer to be between 1 and 4 min.

Experimental protocol. All rats were placed into the testing apparatus for three $30 \mathrm{~min}$ daily sessions to allow adaptation of novelty-induced activation of Fos. From these rats, three groups were randomly selected to represent the acquisition and extinction sessions of fear conditioning, as well as a control group (Table 1$)$. Control rats $(n=6)$ were placed into the apparatus for two $30 \mathrm{~min}$ additional daily sessions. The first session was without any footshock or tones, whereas in the second session, 10 tones without footshock were given. Rats in the acquisition group $(n=$ 7) were given 1 session without tones or shock, followed the next day by the acquisition session of a conditioned fear paradigm: 10 tone with footshock pairings over a $30 \mathrm{~min}$ period. The rats in the extinction group $(n=6)$ were subjected to the acquisition session (10 tones paired with footshock), followed the next day by the extinction session (10 tones without footshock). Previous exposure to this acquisition paradigm resulted in behavioral and biochemical measures of fear during the extinction session (Morrow et al., 1996). The additional habituation sessions in the testing apparatus given to rats in the control and acquisition groups were used to allow the same number of sessions for rats in all three groups and thus minimize any possible effect of differential handling. The rats were videotaped for later analysis of behavior during the last two sessions. At the end of the final session, all rats were returned to their home cages and, after $2 \mathrm{hr}$, were given pentobarbital (Sigma, St. Louis, MO), $65 \mathrm{mg} / \mathrm{kg}$ intraperitoneally, to induce deep anesthesia. These rats were then transcardially perfused with heparin $(1 \mathrm{U} / \mathrm{ml})$ in saline $(0.9 \%$; $50 \mathrm{ml}$ ), followed by $0.1 \mathrm{M}$ phosphate buffered paraformaldehyde $(4 \% ; 250$ $\mathrm{ml}, \mathrm{pH}$ 7.4). The brains were removed and stored overnight in phosphate buffered paraformaldehyde at $4^{\circ} \mathrm{C}$.

Separate groups of rats were treated with sense $(n=3$ each for 12 and $72 \mathrm{hr}$ delays) or antisense ( $n=5$ or 6 for 12 and $72 \mathrm{hr}$ delays, respectively) oligonucleotides $\sim 12$ or $72 \mathrm{hr}$ before the acquisition session. Control rats received injections of the PBS vehicle $(n=3$ each for 12 and $72 \mathrm{hr}$ delays). Rats were anesthetized using halothane (Halocarbon Laboratory, River Edge, NJ) and placed into a stereotaxic instrument (David Kopf, Tujunga. CA) with a heated platform. The skin in the surgical area was shaved, scrubbed with iodine surgical scrub (Schein, Port Washington, NY), and cut, and the top of the skull was exposed and verified to be in the flat skull position. Two small hole were drilled above the $\mathrm{mPFC}$ and $2 \times 30$ ga stainless steel injection cannulas were lowered $3 \mathrm{~mm}$ into the $\mathrm{mPFC}$ ( $3.0 \mathrm{~mm}$ anterior and $0.75 \mathrm{~mm}$ bilateral to bregma). Phosphorothiolated 15-mer sense and antisense oligonucleotides (antisense; 5' GAA-CAT-CAT-GGT-CGT-3') were obtained from Oligonucleotide Synthesis facility at Yale University School of Medicine (New Haven, CT), purified by ethanol precipitation, resuspended in PBS ( $\mathrm{pH}$ 7.4), and quantitated by absorbance spectroscopy. Oligonucleotides (5 nmol in $1 \mu \mathrm{l}$ ) or vehicle were injected using a syringe pump (Harvard Apparatus, Natick, MA) at $0.2 \mu \mathrm{l} / \mathrm{min}$ over $5 \mathrm{~min}$. The ASO sequence, dosage, and presumed duration of action were based on published reports (Chiasson et al., 1992; Hooper et al., 1994). The cannulas were left in place for 5 additional minutes to avoid drawing the oligonucleotide back up the cannula tract. The holes in the skull were sealed with bone wax (Schein), and the incision was area was covered with 5\% xylocaine ointment (Schein) and a topical antibiotic ointment (Tri-thalmic; Schein) and sealed with wound clips. After either a 12 or $72 \mathrm{hr}$ delay, animals were conditioned to fear the tone as by exposure to the acquisition session: 10 tones paired with footshock. Rats were killed $2 \mathrm{hr}$ after the acquisition session and perfused for immunocytochemical analysis as described previously.

In a final experiment, the effect of ASO blocking the acquisitioninduced activation of Fos in the prelimbic (PL)/infralimbic (IL) area on subsequent fearful behavior observed during the extinction session was tested. Rats were treated with sense $(n=6)$ or antisense $(n=7)$ oligonucleotides and, after a $12 \mathrm{hr}$ delay, subjected to the acquisition session. Rats were returned to the home cage for $72 \mathrm{hr}$ and finally tested with an extended extinction session; 20 tones, without footshock, were given over a $1 \mathrm{hr}$ period using the stimuli duration and intertrial interval described previously. The behavior of the animal in response to the conditioned tones was videotaped and assessed by a blinded observer. After the completion of the experiment, rats were killed for histological examination of the injection site using $50 \mu \mathrm{m}$ sections stained with cresyl violet (Morrow et al., 1993). Because no Fos activity was expected during the extinction session (see Results), no sections were stained for Fos.

Immunocytochemistry. After storing overnight in paraformaldehyde, the brains were washed in $1.0 \mathrm{M}$ cold phosphate buffer (PB), $\mathrm{pH} 7.4$, cut on a vibratome into $50 \mu \mathrm{m}$ sections, and stained using standard immunocytochemistry techniques (Leranth and Nitsch, 1994). Some sections were cyropreserved for later analysis. The sections were washed in PB, treated for $10 \mathrm{~min}$ in $1 \%$ sodium borohydride to remove unbound aldehydes and repeatedly rinsed in PB. The sections were then washed briefly with a PB plus $0.3 \%$ Triton X-100 solution and incubated overnight in a rabbit anti-Fos primary antiserum (Ab-2; $1: 400$ dilution in 0.1 M PB plus $0.3 \%$ Triton X-100 plus $0.1 \%$ sodium azide; Oncogene Science, Cambridge, MA). The sections were rinsed in PB plus $0.3 \%$ Triton $\mathrm{X}-100$ and further prepared according to the avidin-biotin complex (ABC) technique (Hsu et al., 1981) using a Vectastain Elite kit (Vector Laboratories, Burlingame, CA) as follows: (1) incubation for $2 \mathrm{hr}$ with a biotinylated goat anti-rabbit secondary antibody (1:250 dilution in PB plus $0.3 \%$ Triton $\mathrm{X}-100$ ); (2) rinsed with $\mathrm{PB}$ (three times for $10 \mathrm{~min}$ ); and (3) incubated in an ABC kit for $2 \mathrm{hr}$ at room temperature. The sections were then washed, and the tissue-bound peroxidase was visualized using a Ni-intensified diaminobenzidine (DAB) reaction $(15 \mathrm{mg}$ of DAB, $40 \mathrm{ml}$ of $\mathrm{PB}, 12 \mathrm{mg}$ of $\mathrm{NH}_{4} \mathrm{Cl}, 0.12 \mathrm{mg}$ of glucose oxidase, $600 \mu \mathrm{l}$ of $0.05 \mathrm{M}$ nickel ammonium sulfate solution, $\mathrm{pH} 6.0$, and $600 \mu \mathrm{l}$ of $10 \% \beta$-Dglucose). Finally, the reaction was terminated by repeated washing with $\mathrm{PB}$, and the sections were mounted on gelatin-coated slides, dehydrated, and covered with coverslips.

Analysis of data. The behavior of the rats during the acquisition and extinction sessions was videotaped for later evaluation. Three major measures of behavior were obtained: (1) fearful behavior associated with the conditioned (tone) or unconditioned (tone-footshock) stimuli; (2) fearful behavior associated with the context (handling, chamber, investigator, etc.); and 3) nonfearful behaviors, including gross exploratory locomotion, vertical locomotion (rearing), and grooming. Tone-specific fearful behavior during the acquisition and extinction sessions was measured by immobility associated with the presentation of the tone, as described previously (Morrow et al., 1996). Briefly, immobility, no visible movement except those necessary for respiration, was scored by an experimenter blinded to each subject's treatment during a 1 min interval after the start of each of the tones. For context-based fearful behavior, the immobility of the rat was measured at the beginning of the extinction session over a 1 min interval after first reexposure to the shock chamber and before any tones had sounded. No tones were given until after this measure had been made. Nonfearful behavioral measures were made over a $20 \mathrm{~min}$ interval starting after a $5 \mathrm{~min}$ adaptation period in the extinction session. This interval included tones. During viewing of the videotaped behavior, the chamber was divided into four equal quadrants by two lines drawn on the screen. Horizontal locomotion was measured 


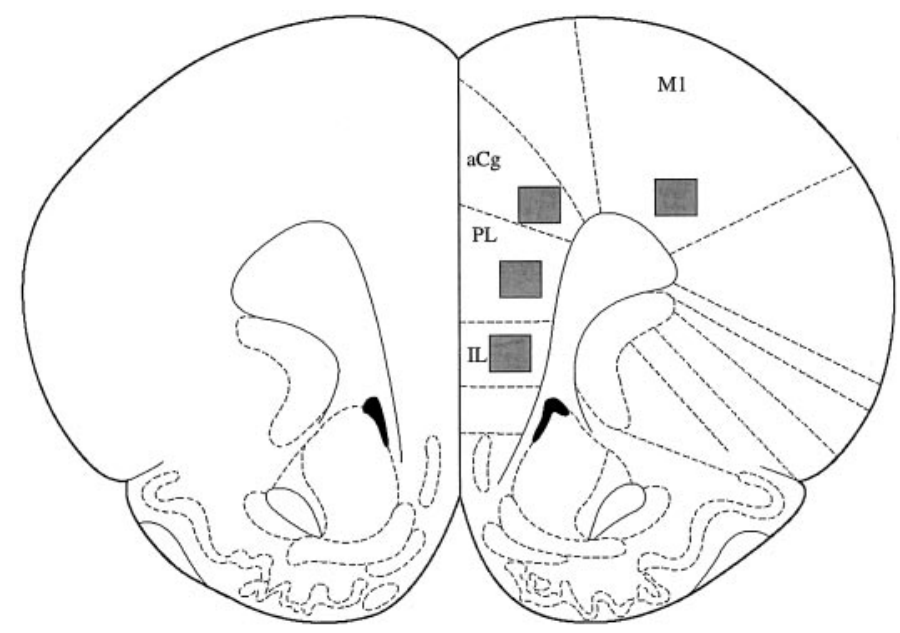

Figure 1. Representation of subregions of the medial prefrontal cortex and the approximate site of the photomicrograph taken. The drawing is from Paxinos and Watson (1997) and represents $2.7 \mathrm{~mm}$ anterior to bregma.

by counting the number of times the base of the tail crossed one of these lines. The time spent grooming and time spent rearing up with the front legs off the floor of the cage (vertical locomotion) were also counted. All statistics were performed on a Macintosh computer using SuperANOVA version 1.11 (Abacus Concepts, Berkeley, CA). Repeated measures ANOVA was used for the behavioral data from the acquisition and extinction sessions with Greenhouse-Geisser correction for covariance (Vitaliano et al., 1981). Univariate analysis of individual time points within the acquisition and extinction sessions were done using one-way ANOVA. In both tests, post hoc testing was performed using the Newman-Keuls range test.

For biochemical measures of Fos activity, Fos-li nuclei were counted in representative areas $\left(0.31 \mathrm{~mm}^{2}\right)$ (Fig. 1) of four subdivisions of the PFC [the IL, PL, anterior cingulate cortex (aCg), and M1 motor cortex (M1)] using a microscope (Olympus BH-2; Olympus Optical, Tokyo, Japan), a CCD camera-frame grabber board (Scion Corp., Frederick, MD), and a MacIntosh computer running the public domain NIH Image (developed at the National Institutes of Health and available on the Internet at http://rsb.info.nih.gov/nih-image). Every fifth section was analyzed between 2.2 and $3.2 \mathrm{~mm}$ anterior to bregma according to Paxinos and Watson (1997) for a total of five sections per animal. The immunocytochemical data from one animal in the acquisition group was lost as a result of technical problems. Initially, one section was photographed and counted visually by three observers (intrarater reliability, $r>0.95$ ). These preliminary results using manual techniques were similar to those obtained using the CCD camera-frame grabber board. To determine the number of Fos-li nuclei in tissue from rats given local injections into the PL/IL, the stained sections that included the lowest point of injection were drawn on a camera lucida, and a $1 \mathrm{~mm}^{2}$ box was drawn around each injection site, as well as the square millimeter above and below. The number of Fos-li nuclei in each square millimeter box were counted by eye instead of using the CCD camera because the cannula tract interfered with automated counting. In two subjects, it was not possible to count Fos-li above the injection site because of the damage from the injection cannula. Repeated measures ANOVA with Newman-Keuls range test was used to determine group differences. Univariate analysis of individual subregions of the PFC were done using one-way ANOVA and Newman-Keuls range test. $p<0.05$ was considered significant.

\section{RESULTS}

\section{Fos immunocytochemistry and behavior during a conditioned fear protocol}

As observed previously (Morrow et al., 1995, 1996, 1997), the behavioral paradigm used in this study rendered rats fearful of a formally neutral tone. For analysis, the behavioral data of all footshocked rats were used (those being killed for biochemical measurement of Fos-li immediately after the acquisition session,
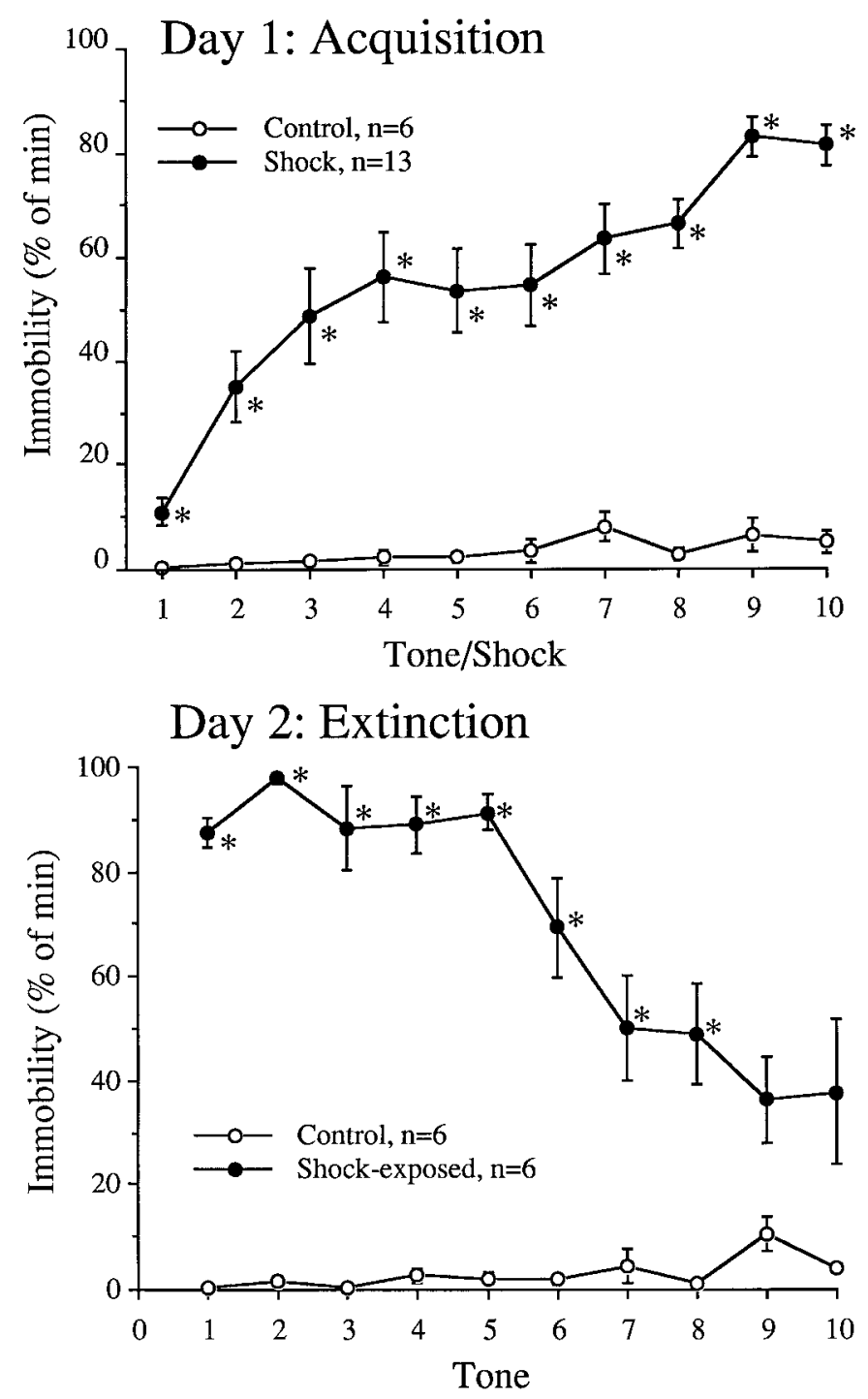

Figure 2. Immobility in rats during the acquisition and expression phases of the conditioned fear paradigm. After $3 \mathrm{~d}$ of habituation to the testing chamber, rats were subjected to a $2 \mathrm{~d}$ paradigm. On day 1 (top), rats were placed into a footshock apparatus and randomly received $105 \mathrm{sec}$ tones paired with $0.5 \mathrm{sec}$ footshocks over a $30 \mathrm{~min}$ period. Control rats received no footshocks. Some controls and footshocked rats were killed after the day 1 session for biochemical analysis. On day 2 (bottom), the remaining rats were returned to the chamber and exposed to $105 \mathrm{sec}$ tones without footshock over a $30 \mathrm{~min}$ period. Seconds spent immobile during $1 \mathrm{~min}$ intervals starting with each of the 10 tones was measured. ${ }^{*} p<0.05$ versus control.

as well as those conditioned fear rats that went on to the extinction session). During acquisition, rats exposed to tones paired with footshock were significantly more immobile than nonshocked rats exposed to the tones alone (acquisition, treatment, $F_{(1,16)}=51.7 ; p<0.0001$; time, $F_{(9,144)}=6.3 ; p<0.0001$; and interaction, $F_{(9,144)}=4.5 ; p=0.007$ ) (Fig. 2). A closer examination revealed that rats receiving footshock remained significantly more immobile than the nonshocked controls at every time point examined. During subsequent exposure to the conditioned tone alone, rats previously exposed to the tone and footshock pairings remained immobile (expression, treatment, $F_{(1,8)}=170.7 ; p<$ 0.0001 ; time, $F_{(9,72)}=4.5 ; p<0.0001$; and interaction, $F_{(9,72)}=$ 


\section{Control}

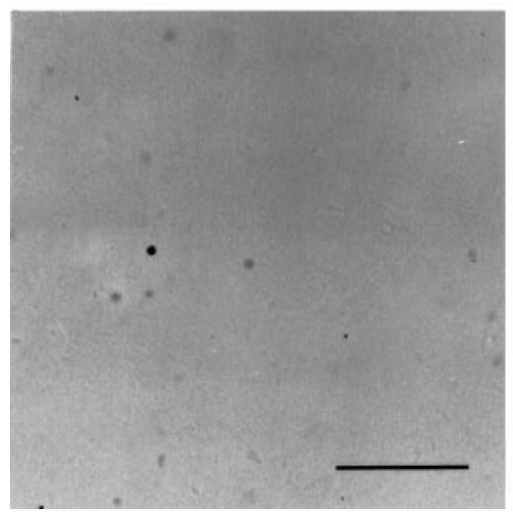

Acquisition

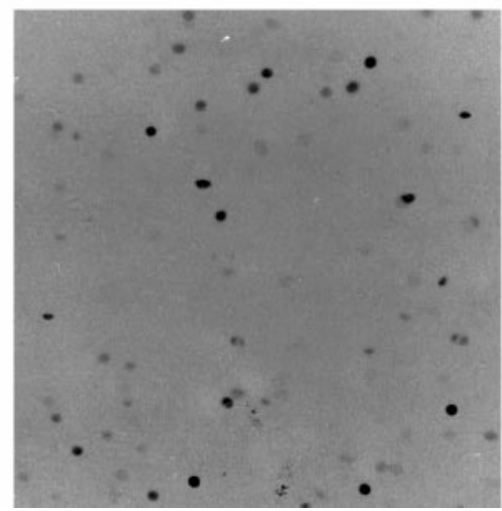

Extinction

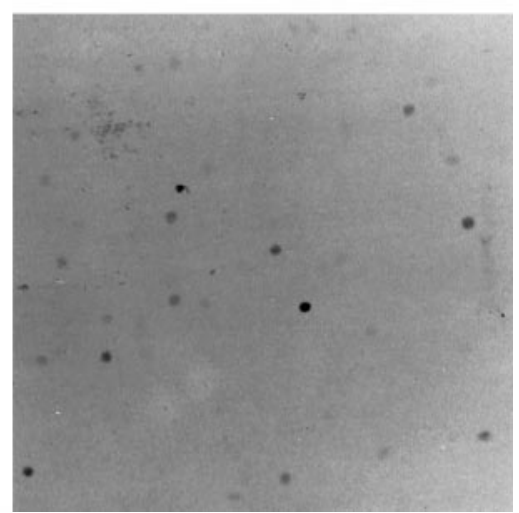

Figure 3. Photomicrographs of the prelimbic region from representative control, acquisition (footshock), and expression animals. Rats previously adapted to the testing chamber underwent a $2 \mathrm{~d}$ test session. On day 1, rats were placed into the chamber for 30 min and received randomized 10 tones alone (Control) or paired with footshock (Acquisition). After this first session, all rats were returned to the home cages, and, after 90 min, rats in the acquisition group and some control rats were killed, and the brain tissues were prepared to visualize Fos-li. On the second day, the remaining rats were returned to the test chamber and exposed to 10 tones without footshock. Rats previously exposed to footshock on day 1 made up the conditioned fear group (Extinction). Ninety minutes after the end of the session, these rats were killed, and Fos-li was visualized in brain tissues. Scale bar, $100 \mu \mathrm{m}$.

6.2; $p=0.004$ ) (Fig. 2). A closer examination revealed that conditioned rats were significantly more immobile after all but the last two tones.

The number of Fos-li nuclei in the IL, PL, aCg, and M1 subdivisions of the prefrontal cortex were analyzed using a CCD camera-image acquisition system. Representative photomicrographs of the PL region from rats undergoing the control, acquisition (footshock), and extinction sessions are shown in Figure 3. Analysis of the number of Fos-li nuclei in each region indicated a significant difference with regard to treatment $\left(F_{(2,15)}=42.2 ; p<\right.$ $0.0001)$, region $\left(F_{(3,45)}=69.4 ; p<0.0001\right)$, and interaction $\left(F_{(6,45)}=24.1 ; p<0.0001\right)$. A closer analysis revealed higher levels of Fos-li nuclei in rats undergoing the acquisition session (tones with footshocks) compared with the controls and those undergoing the extinction session (tones) in the $\operatorname{IL}\left(F_{(2,15)}=26.4\right.$; $p<0.0001)$ and PL $\left(F_{(2,15)}=35.6 ; p<0.0001\right)$ but not the aCg $\left(F_{(2,15)}=3.2 ; p=0.07\right)$ or $\mathrm{M} 1\left(F_{(2,15)}=0.4 ; p=0.65\right)$ (Fig. 4). Rats undergoing the extinction day of the conditioned fear paradigm had significantly more Fos-li than the controls but less than rats undergoing the acquisition session in the PL and IL $(p>0.05)$.

\section{Antisense effects on Fos biochemistry and behavior}

The site of the injection was centered on the lower PL and upper IL cortex region (Figs. 5, 6) with no points of administration located in the aCg subregion. Antisense injections 12, but not 72 , $\mathrm{hr}$ before the acquisition session significantly diminished footshock-induced extinction of Fos-li in the square millimeter surrounding the injection site (Fig. 7, Middle, $F_{(5,17)}=6.07 ; p=$ 0.002 ). The effect was limited to the area immediately surrounding the injections site and did not spread to the square millimeter areas below or above the injection site area (Fig. 7, Upper, $F_{(5,17)}=1.73 ; p=0.18 ;$ Lower, $\left.F_{(5,17)}=0.44 ; p=0.81\right)$. Sense oligonucleotides did not alter the Fos-li at any time or in any region surrounding the injection site. The effects of the ASO were gone by $72 \mathrm{hr}$, and no long-term changes in footshock-induced Fos activation were observed.

The administration of ASO did not alter the acquisition of

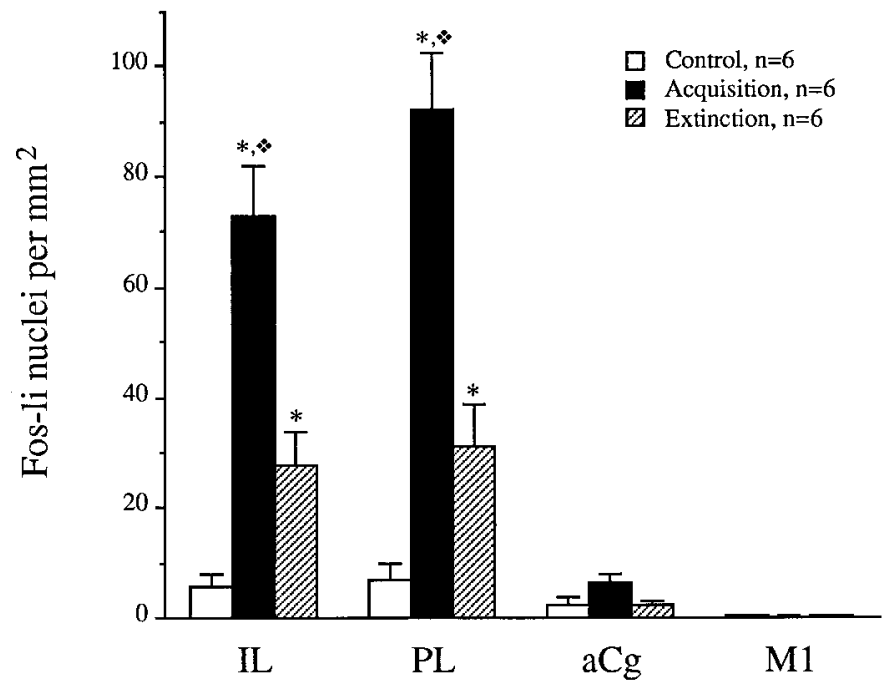

Figure 4. The density of Fos-li-positive nuclei in the subregions of the mPFC of rats undergoing the acquisition (day 1) or expression (day 2) of conditioned fear. Fos-li immunocytochemistry was performed on the brains of rats subjected to the paradigm described in the legend of Figure 2. ${ }^{*} p<0.05$ versus the control group; $* p<0.05$ versus the extinction group of the same region.

footshock-induced immobility in rats treated either 12 or $72 \mathrm{hr}$ earlier (treatment, $F_{(3,34)}=0.65 ; p=0.59$; interaction, $F_{(27,306)}=$ $1.2 ; p=0.19$ ) (Fig. 8). There was, however, a nonsignificant trend for an increase in footshock-induced immobility during the first footshock in control and ASO rats operated on just $12 \mathrm{hr}$ before compared with those operated on $72 \mathrm{hr}$ before. This is likely a result of the difference in delay after surgery affecting the initial reactivity of the rat. Unlike during the acquisition session, previous treatment with ASO 12 hr before the acquisition session resulted in diminished fear-induced immobility during the expression session (treatment, $F_{(1,11)}=26.5 ; p=0.0003$; time, $F_{(19,209)}=4.7 ; p<0.0001$; interaction, $\left.F_{(19,209)}=0.9 ; p=0.62\right)$ (Fig. 9). Changes in contextual-based fear-conditioned immobil- 
A

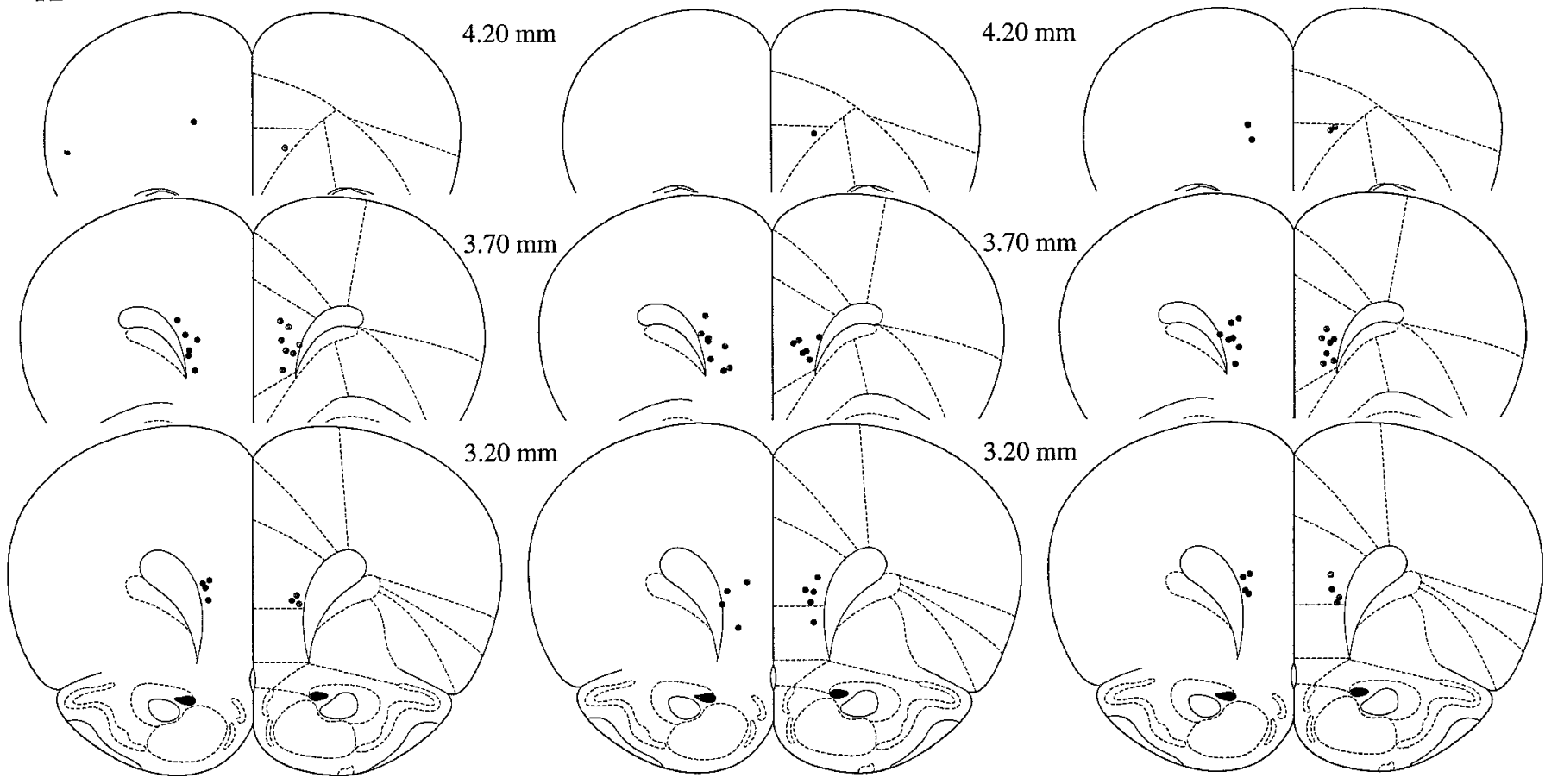

Figure 5. The location of the tip of the injection cannula in rats treated with sense or antisense oligonucleotides in the prelimbic/infralimbic subregion of the medial prefrontal cortex. Three groups of animals are represented here. $A$, Rats treated 12 hr before the acquisition session and killed for immunocytochemistry. $B$, Rats treated $72 \mathrm{hr}$ before the acquisition session and killed for immunocytochemistry. $C$, Rats treated $12 \mathrm{hr}$ before acquisition and tested for expression $72 \mathrm{hr}$ later. The brain drawings are from Paxinos and Watson (1997), and the numbers represent the location of the section in millimeters anterior to bregma.

SO

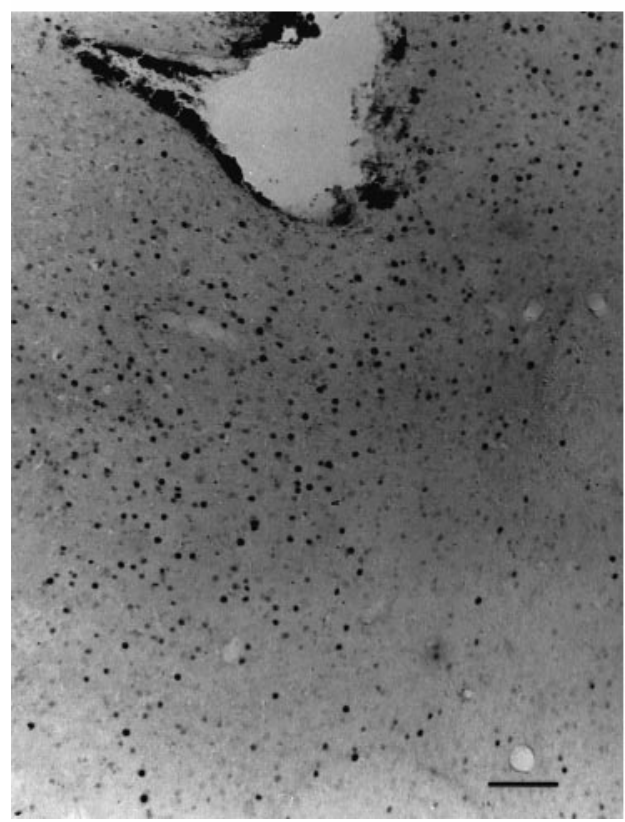

ASO

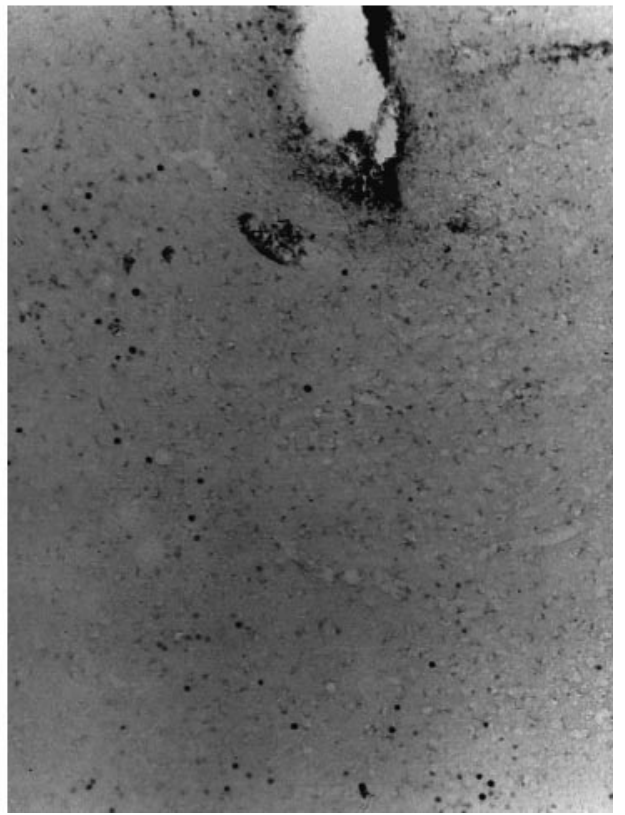

Figure 6. A photomicrograph of a representative injection site from rats injected with either sense oligonucleotide $(\mathrm{SO})$ and ASO. Rats were treated with the oligonucleotides $(5 \mathrm{nmol}$ in $1 \mu \mathrm{l})$ in PBS $12 \mathrm{hr}$ before undergoing the acquisition session (Fig. 2) and killed $90 \mathrm{~min}$ after the end of the $30 \mathrm{~min}$ session. Brains were prepared for visualization of Fos-li. Scale bar, $100 \mu \mathrm{m}$.

ity were not significantly different $\left(F_{(1,11)}=1.23 ; p=0.29\right)$ (Table $2)$. Differences in measures of nonfear-related behaviors were noted. Treatment with ASO $12 \mathrm{hr}$ previously increased the measures of horizontal exploratory locomotion (line crossings) and vertical locomotion (rearing) but not grooming during the extinction session (line crossings, $F_{(1,11)}=11.4 ; p=0.006$; rearing, $F_{(1,11)}=5.51 ; p=0.039 ;$ grooming, $\left.F_{(1,11)}=1.06 ; p=0.32\right)$ (Table 2). 


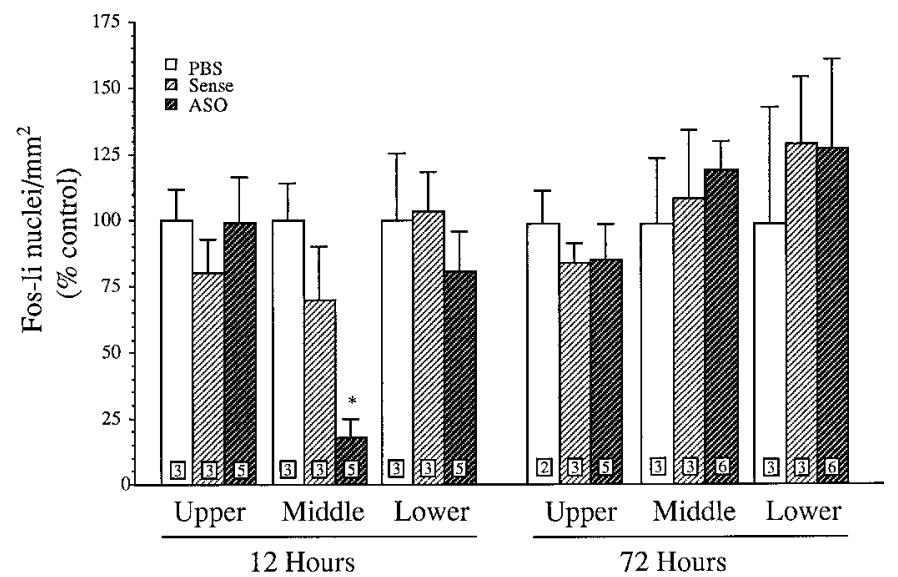

Figure 7. The density of Fos-li positive nuclei in the square millimeter area surrounding (Middle), above, or below the injection site of PBS, sense oligonucleotide $(S O)$, or ASO. Brain sections from treat rats that underwent the acquisition session of fear conditioning were visualized for Fos-li and drawn on a camera lucida system. The number of Fos-li nuclei were counted in each square millimeter area. ${ }^{*} p<0.05$ versus the PBS control group within the same area.

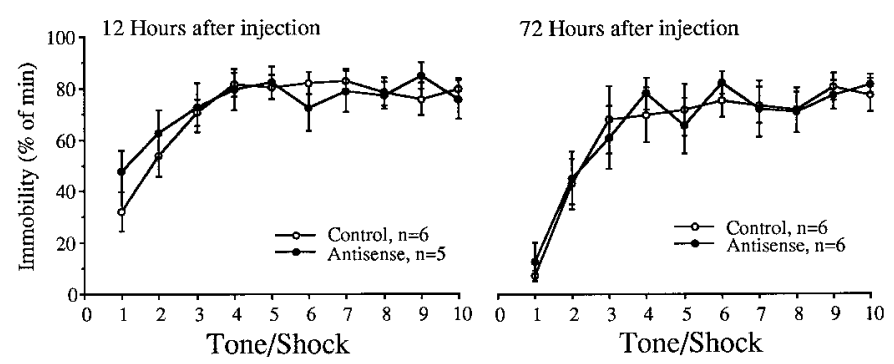

Figure 8. The lack of an effect of antisense oligonucleotide treatment, given either 12 or $72 \mathrm{hr}$ before, on behavior during the acquisition session. Rats were treated with sense oligonucleotides $(S O)$, ASO, or vehicle and, after a 12 or $72 \mathrm{hr}$ delay, subjected to the acquisition session of the conditioned fear protocol (Fig. 2). The behavior of the sense oligonucleotide-treated and vehicle-treated controls were not different and were combined into a single control group for graphic purposes only. Immobility was measured for each tone plus footshock pairing over a 1 min interval. There was no difference between the sense oligonucleotideor ASO-treated groups at either 12 or $72 \mathrm{hr}$.

\section{DISCUSSION}

In this communication, we report two main findings. (1) Using a mild aversive conditioning protocol, Fos protein was more strongly activated in association with the acquisition of fear than with the expression of fear. (2) Blocking the acquisition-induced Fos production in the PL and IL cortex was associated with a dramatic reduction in the expression of fear-related behaviors at a time when the ASO was no longer active in the brain.

Previous studies have proposed a role for Fos and other immediate-early genes in the process of learning (for review, see Dragunow, 1996). However, some questions have been raised as to the contribution of novelty and stress to the Fos activation during the learning task (Asanuma and Ogawa, 1994; Dragunow, 1996). The first of these concerns was addressed in this current report by habituating the subjects to the testing environment, thus suppressing novelty-induced Fos activation. The second point of concern was that stress, independent of any learning paradigm, has been noted to increase Fos activation (Deutch et al., 1991; Schreiber et al., 1991; Smith et al., 1992; Melia et al., 1994;

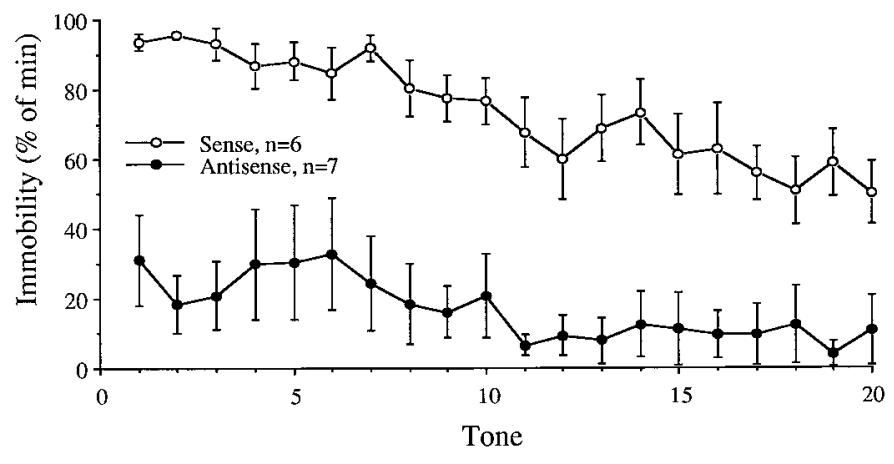

Figure 9. The effect of antisense oligonucleotide blockade of acquisitioninduced Fos-li on the later expression of conditioned fear. Rats were treated with either sense (SO) or antisense (ASO) oligonucleotides and, after $12 \mathrm{hr}$, subjected to the acquisition session of conditioned fear (Fig. 2 ). Three days later, $\sim 84 \mathrm{hr}$ after oligonucleotide treatment, rats underwent the expression session of the conditioned fear protocol. ASO-treated rats showed significantly less fear-induced immobility than the sense oligonucleotide-treated controls at every time point tested.

Table 2. Measures of contextual-based fear and nonfearful behaviors

\begin{tabular}{lcc} 
& $\begin{array}{l}\text { Sense } \\
(n=6)\end{array}$ & $\begin{array}{l}\text { Antisense } \\
(n=7)\end{array}$ \\
\hline $\begin{array}{l}\text { Context-based fear } \\
\text { Immobility (\% min) }\end{array}$ & $29.2 \pm 7.9$ & $15.0 \pm 8.5$ \\
Locomotion & & \\
$\quad$ Horizontal (lines crossed) & $2.8 \pm 1.5$ & $65.0 \pm 17.7^{*}$ \\
$\quad$ Vertical (seconds spent rearing) & $2.0 \pm 1.3$ & $72.3 \pm 28.5^{*}$ \\
Grooming (sec) & $64.8 \pm 39.3$ & $142.5 \pm 58.6$ \\
\hline
\end{tabular}

Rats were treated with sense or antisense oligonucleotides $12 \mathrm{hr}$ before the acquisition session and then $3 \mathrm{~d}$ later subjected to the expression session of a conditioned fear protocol. $p<0.05$ versus sense-treated control.

Duncan et al., 1996). The Fos activation during the acquisition session, however, does not appear to be simply caused by a nonspecific stress response, because a smaller increase of Fos activation was noted in the PL/IL during the extinction phase, an interval with robust changes in behavioral and biochemical correlates of stress (Morrow et al., 1995, 1996, 1997). This suggests that, in this study, Fos activation in the mPFC is not simply related to stress or novelty but is associated with the acquisition or learning of this aversive conditioning paradigm. Several laboratories, however, have demonstrated increased Fos in regions other than the mPFC during the extinction period of a conditioned stressor (Campeau et al., 1991; Smith et al., 1992; Beck and Fibiger, 1995). Beck and Fibiger (1995) have shown a conditioned fear-induced increase in Fos-li in the $\mathrm{aCg}$ using a more severe shock paradigm (150 $1 \mathrm{sec}$ footshocks of unknown intensity per $30 \mathrm{~min}$ session for three sessions). Whereas the acquisition period is believed to reflect learning, the extinction period is thought to reflect the development of inhibition rather than the deletion of the acquired memory (Pavlov, 1927; Konorski, 1967; Bouton and Bolles, 1979; Rescorla, 1979; Wagner, 1981). Therefore, any observed Fos activation during extinction may be involved in the inhibition, rather than "unlearning," of the fearful behavior.

The role of Fos in aversive learning is supported by the results of ASO blockade presented here. The blockade of Fos production during the acquisition session diminished the subsequent expression of fearful behavior, as well as increased the expression of nonfearful exploratory behaviors. No acute effects of ASO on 
behavior were noted, decreasing the likelihood that the ASO simply disrupted the acquisition of conditioned fear. Additionally, no long-term changes in Fos expression were noted when the ASO was given $72 \mathrm{hr}$ before the acquisition session, indicating that it is unlikely that any ASO activity was present during the extinction session. Previous studies demonstrated that this Fos ASO had no significant activity after 22-24 hr (Chiasson et al., 1992; Hooper et al., 1994). Because the Fos protein is created several hours after the initial stressful event, it is likely that Fos is involved in the biochemical mechanism of consolidation of the fearful memory, in agreement with the proposed role of Fos in learning and memory (Dragunow, 1996). Alternatively, other explanations must be considered. In this current study, statedependent learning specific for the ASO cannot be ruled out. This is not likely because (1) previous learning studies with ASO directed against Fos protein have not indicated state-dependent effects (Mileusnic et al., 1996) and, (2) if state-dependent learning effects were present, they would have to be specific for the ASO but not the sense oligonucleotide. The role of Fos in the molecular mechanisms of learning and memory has been difficult to validate. Previously, other researchers have not been able to observe selective changes in learning because of changes in behavior during training likely induced by the antisense blockade at that time (Chiasson et al., 1992; Heilig et al., 1993; Hooper et al., 1994; Moller et al., 1994; Hunter et al., 1995). We were able to overcome this obstacle by (1) selecting an aversive task that involves a select group of behaviors not normally expressed under controlled conditions, (2) selecting a brain region thought to have a modulatory, rather than primary, role in the expression of fearful behaviors, and (3) using a task with a very short duration of acquisition (30 $\mathrm{min})$.

The Fos activation in the mPFC demonstrated a selective regional pattern appearing in the medial but not lateral (motor) prefrontal cortex. Anatomical studies of the subregions within the mPFC differ somewhat in the projection fields based on corticocortical afferents (van Eden et al., 1992). The dorsal mPFC, including the $\mathrm{aCg}$, has been demonstrated to have connections involving somatosensory and nonprimary motor function (van Eden et al., 1992). The ventral mPFC, the PL and IL together, seem to correspond to a limbic-related projection field receiving input from perirhinal cortex areas, as well as direct and indirect connections with limbic structures, such as the amygdala, olfactory structures, nucleus accumbens, hypothalamus, and hippocampus (Kita and Oomura, 1981; Swanson, 1981; Price and Slotnick, 1983; Van Vulpen and Verwer, 1989; Sesack et al., 1989; Hurley et al., 1991; van Eden et al., 1992). Together, the strong Fos activation to the PL and IL seems to indicate a role for the limbic-related neuronal system in the acquisition of aversive conditioning.

The role of the mPFC itself in conditioned fear is not clear but is thought to be modulatory in nature. Lesions of the mPFC have resulted in mixed results, including increasing (Morgan et al., 1993; Morgan and LeDoux, 1995), decreasing (Frysztak and Neafsey, 1991), and not altering (Gewirtz et al., 1997) the fear response. It is likely that differences in these studies, such as the extent and type of lesions, the training protocols, and other factors that could alter the extent of conditioning or allow the neuronal adaptation to the lesion, could contribute to this confusion. In our laboratory, differences in the extent of excitotoxic lesions of the ventral mPFC using two different lesioning protocols has resulted in divergent effects on fear behaviors (our unpublished observations). For these reasons, we have chosen less invasive approaches to investigate the role of the mPFC in fear, including the approach presented in this current report. Additionally, we have recently attempted to eliminate the stressinduced increase in dopamine in the $\mathrm{mPFC}$ by dopaminergic lesion (Morrow et al., 1999a) and by use of selective pharmacological agents (Morrow et al., 1999b). These studies indicate that the $\mathrm{mPFC}$ has a modulatory, rather than primary, role in the expression of fear.

We do not know the exact mechanism by which Fos in the $\mathrm{mPFC}$ is involved in aversive learning. Electrophysiological studies have demonstrated long-term potentiation and depression of excitatory potentials in pyramidal cells in layer $\mathrm{V}$ of the prefrontal cortex (Hirsch and Crepel, 1990; Law-Tho et al., 1995). Such long-term changes, which can be induced in seconds but remain for extended intervals (up to weeks), have been proposed to be a mechanism of learning (Bliss and Collingridge, 1993; Izquierdo, 1993). Dopamine, a neurotransmitter activated by the conditioned fear protocol used in this report (Morrow et al., 1995, 1996, 1997), has been demonstrated to induce long-term depression in cells in layer V of the prefrontal cortex (Law-Tho et al., 1994, 1995). It is possible that, through these changes in excitability and subsequent secondary messenger systems, modified transcription and translation of Fos and other immediate-early genes occurs (Dragunow, 1996). This cascade in genetic activity presumably leads to long-term alterations in the neuronal biochemistry or structure which, in turn, are behaviorally expressed as, at least part of, the acquisition of fear conditioning. This presumption is supported by the behavioral results of ASO blockade of Fos-li presented here.

In conclusion, these studies report a selective activation of Fos-li in the mPFC during the learning phase of a conditioned fear paradigm, which we propose to be involved in the cellular mechanism of aversive learning. From the effects of the blockade of the expression of Fos, we conclude that Fos in the IL and PL maybe necessary for the consolidation and subsequent expression of fearful memories.

\section{REFERENCES}

Asanuma M, Ogawa N (1994) Pitfalls in assessment of c-fos mRNA expression in the brain: effects of animal handling. Rev Neurosci 5:171-178.

Beck CHM, Fibiger HC (1995) Conditioned fear-induced changes in behavior and in the expression of the immediate early gene c-fos: with or without diazepam pretreatment. J Neurosci 15:709-720.

Bliss TVP, Collingridge GL (1993) A synaptic model of memory: longterm potentiation in the hippocampus. Nature 361:31-39.

Bouton ME, Bolles RC (1979) Contexts, event-memories, and extinction. In: Context and learning (Balsam PD, Tomie A, eds), Hillsdale, NJ: Erlbaum.

Campeau S, Hayward MD, Hope BT, Rosen JB, Nestler EJ, Davis M (1991) Induction of the c-fos proto-oncogene in rat amygdala during unconditioned and conditioned fear. Brain Res 565:349-352.

Chiasson BJ, Hooper,ML, Murphy PR, Robertson HA (1992) Antisenseoligonucleotide eliminates in vivo expression of $c$-fos in mammalian brain. Eur J Pharmacol Mol Pharmacol Sect 227:451-453.

Deutch AY, Roth RH (1990) The determinants of stress-induced activation of the prefrontal cortical dopamine system. In: Progress in brain research (Uylings HBM, Van Eden CG, De Bruin JPC, Corner MA, Feenstra MGP, eds). Amsterdam: Elsevier.

Deutch AY, Lee MC, Gillham MH, Cameron DA, Goldstein M, Iadarola MJ (1991) Stress selectively increases Fos protein in dopaminergic neurons innervating the prefrontal cortex. Cereb Cortex 1:273-292.

Dragunow M (1996) A role for immediate-early transcription factors in learning and memory. Behav Genet 26:293-299.

Duncan GE, Knapp DJ, Breese GR (1996) Neuroanatomical characterization of Fos induction in rat behavioral models of anxiety. Brain Res 713:79-91. 
Frysztak RJ, Neafsey EJ (1991) The effect of medial frontal cortex lesions on respiration, "freezing" and ultrasonic vocalizations during conditioned emotional responses in rats. Cereb Cortex 1:418-425.

Gewirtz JC, Falls WA, Davis MD (1997) Normal conditioned inhibition and extinction of freezing and fear potentiated startle following electrolytic lesions of medial prefrontal cortex. Behav Neurosci 111:712-726.

Goldman-Rakic PS (1987) Development of cortical circuitry and cognitive function. Child Dev 58:601-622.

Graybiel AM, Moratalla R, Robertson HA (1990) Amphetamine and cocaine induced drug-specific activation of the c-fos gene in striosomematrix and limbic subdivisions of the striatum. Proc Natl Acad Sci USA 87:6912-6916.

Heilig M, Engel JA, Soderpalm B (1993) C-fos antisense in the nucleus accumbens blocks the locomotor stimulant action of cocaine. Eur J Pharmacol 236:339-340.

Hirsch JC, Crepel F (1990) Use-dependent changes in synaptic efficacy in rat prefrontal neurons in vitro. J Physiol (Lond) 432:123-141.

Hoffman GE, Smith MS, Fitzsimmons MD (1992) Detecting steroidal effects on immediate early gene expression in the hypothalamus. Neuroprotocols 1:52-66.

Hooper ML, Chiasson BJ, Robertson HA (1994) Infusion into the brain of an antisense oligonucleotide to the immediate-early gene $c$-fos suppresses production of fos and produces a behavioral effect. Neuroscience 63:917-924.

Hsu SM, Raine L, Franger H (1981) The use of avidin-biotin-peroxidase complex $(\mathrm{ABC})$ in immunoperoxidase techniques: a comparison between $\mathrm{ABC}$ and unlabeled antibody (peroxidase) procedures. J Histochem Cytochem 29:577-590.

Hunter JC, Woodburn VL, Durieux C, Pettersson EKE, Poat JA, Hughes J (1995) C-fos antisense oligodeoxynuceotide increases formalininduced nociception and regulates preprodynorphin expression. Neuroscience 65:485-492.

Hurley KM, Herbert H, Moga MM, Saper CB (1991) Efferent projections of the infralimbic cortex in the rat. J Comp Neurol 308:249-276.

Izquierdo I (1993) Long-term potentiation and the mechanism of memory. Drug Dev Res 30:1-17.

Kita H, Oomura Y (1981) Reciprocal connection between the lateral hypothalamus and the prefrontal cortex in the rat: electrophysiological and anatomical observations. Brain Res 213:1-16.

Konorski J (1967) Integrative activity of the brain. Chicago: University of Chicago.

Law-Tho D, Desce JM, Crepel F (1995) Dopamine favours the emergence of long-term depression versus long-term potentiation in slices of rat prefrontal cortex. Neurosci Lett 188:125-128.

Law-Tho D, Hirsch JC, Crepel F (1994) Dopamine modulation of synaptic transmission in rat prefrontal cortex: an in vitro electrophysiological study. Neurosci Res 21:151-160.

Leranth C, Nitsch R (1994) Morphological evidence that hypothalamic substance P-containing afferents are capable of filtering the signal flow in the monkey hippocampal formation. J Neurosci 14:4079-4094.

Mack KJ, Mack PA (1992) Induction of transcription factors in somatosensory cortex after tactile stimulation. Mol Brain Res 12:141-147.

Melia KR, Ryabinin AE, Schroeder R, Bloom FE, Wilson MC (1994) Induction and habituation of immediate early gene expression in rat brain by acute and repeated restraint stress. J Neurosci 14:5929-5938.

Mileusnic R, Anokhin K, Rose SP (1996) Antisense oligodeoxynucleotides to c-fos are amnestic for passive avoidance in the chick. NeuroReport 7:1269-1272.

Moller C, Bing O, Heilig M (1994) C-fos expression in the amygdala: in vivo antisense modulation and role in anxiety. Cell Mol Neurobiol 14:415-423.

Morgan JI, Curran T (1991) Stimulus-transcription coupling in the nervous system: involvement of the inducible proto-oncogenes fos and jun. Annu Rev Neurosci 14:421-451.

Morgan MA, LeDoux JE (1995) Differential contribution of dorsal and ventral medial prefrontal cortex to the acquisition and extinction of conditioned fear in rats. Behav Neurosci 109:681-688.
Morgan MA, Romanski LM, LeDoux JE (1993) Extinction of emotional learning: contribution of medial prefrontal cortex. Neurosci Lett 163:109-113.

Morrow BA, Clark WA, Roth RH (1993) Stress activation of mesocorticolimbic dopamine neurons: effects of a glycine/NMDA receptor antagonist. Eur J Pharmacol 238:255-262.

Morrow BA, Taylor JR, Roth RH (1995) Prior exposure to cocaine diminishes behavioral and biochemical responses to aversive conditioning: reversal by glycine/ $\mathrm{N}$-methyl-D-aspartate antagonist co-treatment. Neuroscience 69:233-240.

Morrow BA, Elsworth JD, Roth RH (1996) Tyrosine enhances behavioral and mesocorticolimbic dopaminergic responses to aversive conditioning. Synapse 22:100-105.

Morrow BA, Lee EJK, Taylor JR, Elsworth JD, Nye HE, Roth RH (1997) $S$ (-)-HA-966, a $\gamma$-hydroxybutyrate-like agent, prevents enhanced mesocorticolimbic dopamine metabolism and behavioral correlates of restraint stress, conditioned fear and cocaine sensitization. J Pharmacol Exp Ther 283:712-721.

Morrow BA, Elsworth JD, Rasmusson AM, Roth RH (1999a) The role of mesoprefrontal dopamine neurons in the acquisition and expression of conditioned fear in the rat. Neuroscience, in press.

Morrow BA, Elsworth JD, Zito CR, Roth RH (1999b) Biochemical and behavioral anxiolytic-like effects of $R(+)$ HA-966 at the level of the ventral tegmental area in rats. Psychopharmacology, in press.

Pavlov IP (1927) Conditioned reflexes: an investigation of the physiological activity of the cerebral cortex. New York: Dover.

Paxinos G, Watson C (1997) The rat brain in stereotaxic coordinates. New York: Academic.

Posner MI (1994) Attention: the mechanisms of consciousness. Proc Natl Acad Sci USA 91:7398-7403.

Price JL, Slotnick BM (1983) Dual olfactory representation in the rat thalamus: an anatomical and electrophysiological study. J Comp Neurol 215:63-77.

Rescorla RA (1979) Conditioned inhibition and extinction. In: Mechanisms of learning and motivation: a memorial volume to Jerzy Konorski. (Dickinson A, Boakes RA, eds). Hillsdale, NJ: Erlbaum.

Schreiber SS, Tocco G, Shors TJ, Thompson RF (1991) Activation of immediate early genes after acute stress. NeuroReport 2:17-20.

Sesack SR, Deutch AY, Roth RH, Bunney BS (1989) Topographical organization of the efferent projections of the medial prefrontal cortex in the rat: an anterograde tract-tracing study with Phaseolus vulgaris leucoagglutinin. J Comp Neurol 290:213-242.

Sharp FR, Sagar SM, Hicks K, Lowenstein D, Hisanaga K (1991) c-fos mRNA, Fos, and Fos-related antigen induction by hypertonic saline and stress. J Neurosci 11:2321-2331.

Smith MA, Banerjee S, Gold PW, Glowa J (1992) Induction of c-fos mRNA in rat brain by conditioned and unconditioned stressors. Brain Res 578:135-141.

Stuss DT, Benson DF (1986) The frontal lobes. New York: Raven.

Swanson LW (1981) A direct projection from Ammon's horn to prefrontal cortex in the rat. Brain Res 217:150-154.

van Eden CG, Lamme VAF, Uylings HBM (1992) Heterotopic cortical afferents to the medial prefrontal cortex in the rat. A combined retrograde and anterograde tracer study. Eur J Neurosci 4:77-97.

Van Vulpen EHS, Verwer RWH (1989) Organization of projections from the mediodorsal nucleus of the thalamus to the basolateral complex of the amygdala in the rat. Brain Res 500:389-394.

Vitaliano PP, Prinz P, Vitiello MV, Olshan A, Roehers TA (1981) On the use of repeated measures designs in psychopharmacology. Psychopharmacology 72:247-249.

Wagner AR (1981) A model of automatic memory processing in animal behavior. In: Information processing in animals: memory mechanisms. (Spear NE, Miller RR, eds). Hillsdale, NJ: Erlbaum.

Young ST, Porrino LJ, Iadarola MJ (1991) Cocaine induced striatal c-Fos-immunoreactive proteins via dopaminergic D1 receptors. Proc Natl Acad Sci USA 88:1291-1295. 